\title{
Alpha band EEG coherence in healthy nonagenarians
}

\author{
Coerência da banda alfa do EEG em nonagenários saudáveis
}

Mario Silva Jorge', Livia Spindola ${ }^{1}$, Joyce Haruyo Biancon Katata ${ }^{2}$, Renato Anghinah ${ }^{1}$

\begin{abstract}
Electroencephalographic (EEG) coherence is a parameter that enables evaluation of cerebral connectivity. It may be related to the functional state of the brain. In the elderly, it may reflect the neuronal loss caused by aging. Objective: To describe characteristics of coherence in nonagenarians. Methods: We evaluated interhemispheric coherence for the alpha band in 42 cognitively normal individuals aged 90 to 101 years. Coherence values in the occipital electrode (0102), in the resting state with closed eyes, were calculated by means of spectral analysis using digital EEG EMSA 32 channels, 12 bits and a frequency of $200 \mathrm{~Hz}$. Results: The mean coherence value for the alpha band at 0102 was 0.65 (SD 0.13). No significant differences were found between men and women. Conclusions: The findings from this study did not show any decrease in interhemispheric coherence for the alpha band in cognitively normal nonagenarians. This may be useful as a standard value for this age group.
\end{abstract}

Keywords: electroencephalography; aged, 80 and over; health of the elderly; aging.

\section{RESUMO}

A coerência é um parâmetro que permite avaliar a conectividade cerebral, podendo se relacionar com o estado funcional do cérebro. Especialmente nos idosos, pode refletir a perda neuronal decorrente do envelhecimento. Objetivo: Descrever características da coerência em nonagenários. Métodos: Avaliamos a coerência interhemisferica para a banda alfa em 42 indivíduos cognitivamente normais entre 90 e 101 anos. Foram calculados através da análise espectral o valor da coerência nos eletrodos 0102, em estado de repouso e olhos fechados, com EEG digital 32 canais marca EMSA 12 bits e frequência de amostragem 200 hz. Resultados: 0 valor médio da coerência para a banda alfa entre 0102 foi de 0,65 (DP 0,13). Não encontramos diferenças significativas entre homens e mulheres. Conclusão: Os achados desse estudo não evidenciam diminuição da coerência interhemisferica para a banda alfa nos eletrodos 0102 em nonagenários saudáveis e cognitivamente normais, podendo indicar um valor padrão para essa faixa etária.

Palavras-chave: eletroencefalografia; idoso de 80 anos ou mais; saúde do idoso; envelhecimento.

Brain tissue has an enormous quantity of connections between neurons. These become established so that neuronal activities become synchronous and different brain areas can communicate. One of the mathematical parameters that enable measurement of this connectivity is electroencephalographic (EEG) coherence. Several published studies have suggested that this coherence decreases through the aging process, with reduction of the neuron population ${ }^{1}$.

Life expectancy in Brazil has increased over recent years and, consequently, the population of nonagenarians has increased. Therefore, there is a need for knowledge of the neurophysiological characteristics of EEG signals in cognitively normal individuals of this age.
Investigation of EEG coherence enables measurement of the correlation between different brain areas. This is done through examining the mutual relationship between two EEG signals for different frequency bands. Quadratic or ordinary coherence consists of measurement of the covariance of spectral power between two pairs of electrodes ${ }^{1,2,3}$. Because coherence is a normative value for the power of a given frequency, it is independent of the amplitude oscillations of the signal ${ }^{4,5}$. Thus, this property makes coherence a relatively safe method for comparing groups of individuals, because differences in EEG potency do not affect the estimated coherence value $^{6}$. Diminished coherence between two regions probably indicates a decrease in their functional correlations ${ }^{1,7}$.

${ }^{1}$ Universidade de São Paulo, São Paulo SP, Brasil;

¿UNEP Unidade Neuropsiquiátrica, São José dos Campos SP, Brasil.

Correspondence: Mario Silva Jorge; Rua Santa Clara, 460; São José dos Campos SP, Brasil; Email: masijor50@gmail.com

Conflict of interest: There is no conflict of interest to declare.

Received 01 June 2017; Accepted 20 June 2017. 
It is possible to calculate the ordinary coherence between two brain electrodes that are placed in the same hemisphere, or in homologous areas, through a mathematical formula that divides the cross-spectrum of these two channels by the product of the auto-spectrum of each of the same channels, as demonstrated by the formula below:

$$
\operatorname{Co}(f) 2=\frac{\{\operatorname{Gxy}(f)\}^{2}}{\operatorname{Gxx}(f) \operatorname{Gyy}(f)}
$$

Co is the coherence function

Gxx and Gyy are the spectral power of each channel

Gxy is the power of the cross-spectrum

The coherence value between two electrodes varies from 0 to 1 , where 1 means the maximum correlation, and 0 means that the correlation is very small or absent ${ }^{5}$. Other studies, such as that by Koyama et al. ${ }^{8}$, who evaluated 68 normal elderly people (61-90 years old) compared to 20 young people (23-50 years), showed that age had no effect on interhemispheric coherence, although intrahemispheric coherence was reduced in all bands, almost linearly.

Anghinah et al. $^{2}$ did not find any significant differences in interhemispheric coherence for the alpha band between individuals in older age groups and young adults. Jorge et al. ${ }^{3}$ studied a population of normal adults and did not observe any influence from age, gender or manual dominance regarding interhemispheric coherence values, for any of the frequency bands evaluated.

Thus, the objective of the present study was to analyze interhemispheric coherence between 0102 electrodes in a population of cognitively normal nonagenarians.

\section{METHODS}

In this study, 80 individuals aged 90 years or older were evaluated. These individuals were recruited from the community or were among a group of elderly patients followed up at the outpatient clinic of the Cognitive and Behavioral Neurology Group and the Reference Center for Cognitive Disorders of the Neurological Clinical Division of Hospital das Clínicas, University of São Paulo Medical School, in São Paulo, or were from sheltered housing for elderly people in São José dos Campos.

Out of this total, 42 participants, who were cognitively normal according to the Mayo Clinic's Older Americans Normative Studies 1992 criteria $^{9}$, were included (52.5\%). These participants did not present with any complaints regarding memory and all of them were living independently. None of them had any disease that could compromise their cognitive functions and none of them were using any medication with psychotropic effects or any effects on cognition.

They underwent an interview, a neurological clinical examination, a neuropsychological evaluation and a digital EEG.
The cognitive assessment followed a protocol that included the Mini-Mental State Examination (MMSE) $)^{10}$, Pfeffer's Functional Activities Questionnaire ${ }^{11}$, Katz assessment $^{12}$, Dementia Rating Scale ${ }^{13}$, verbal fluency evaluation (semantic and phonemic) and digit repetition assessment in direct order and inverse order.

All the subjects underwent electroencephalography in a silent environment, with closed eyes, after having been at rest for a period of 30 minutes. The recording used digital low-pass and high-pass filters with cutoff frequencies at 0.5 and $30 \mathrm{~Hz}$.

The electrode placement system followed the 10-20 standard as recommended by the Brazilian Society of Clinical Neurophysiology ${ }^{14,15}$. The electrode impedance was less than 5.0 ohms and a technically-linked binaural reference was used, which is the most appropriate form for this type of recording ${ }^{16-18}$.

From these recordings, 20 records of 2.56 seconds each were selected. These were free from artifacts, such as eye movements, eyelid movements and muscle potentials, and were free from transient findings such as benign variants ${ }^{19}$. The fast Fourier transform was applied to obtain spectral analyses with the respective values for each region of the scalp. After obtaining the spectra, the interhemispheric coherence was calculated for all the bands. The equipment used was an EMSA Braintech digital EEG system with 32 channels, $200 \mathrm{~Hz}$ sampling frequency and 12-bit processor, with software capable of performing quantitative evaluations and coherence analyses through application of the fast Fourier transform.

All the participants agreed to undergo the protocol by signing a free and informed consent statement, which was done either by the individuals themselves or by a member of their family. This project was approved by the Ethics Committee for Analysis of Research Projects (CAPPesp), which is part of the Clinical Board of Hospital das Clínicas, University of São Paulo Medical School, under number 0500/10.

\section{RESULTS}

Among the 80 individuals who underwent neuropsychological assessment, 33 were excluded because they presented with mild cognitive impairment or even the beginnings of dementia. Five of the potential participants dropped out, i.e. they decided that they did not want to complete the evaluation, for a variety of reasons. The remaining 42 individuals met the inclusion criteria. In this study, the ages of the participants ranged from 90 to 101 years, with an average of 92 (SD 3), with the largest proportion of them being 90 years of age (39\%) (Table 1 ).

The educational level ranged from 0 (illiterate) up to 19 years, with an average of nine years (SD 4.60). Regarding the gender of the individuals studied, 29\% (12) were male and $71 \%$ (30) were female. The MMSE scores ranged from 20 to 30 , and the mean was 27.14 (SD 2.60). The individual with the 
Table 1. Sample characteristics.

\begin{tabular}{lc}
\hline Variable & $\mathrm{n}(\%)$ \\
\hline Age (years) & $38(90.47)$ \\
\hline $90-95$ years & $3(7.14)$ \\
\hline $95-100$ years & $1(2.38)$ \\
\hline 100 years & \\
\hline Gender & $12(29)$ \\
\hline Men & $30(71)$ \\
\hline Women & \\
\hline Schooling level & $12(28.60)$ \\
\hline $0-5$ years & $10(23.80)$ \\
$6-10$ years & $15(35.70)$ \\
\hline $11-15 y e a r s$ & $5(11.90)$ \\
$>15 y e a r s$ & $42(100)$ \\
\hline Total
\end{tabular}

lowest MMSE score (20) was the one with the lowest level of education. The largest proportion of the participants (10 individuals; 23.80\%) had an MMSE score of 29.

The Pfeffer Functional Activities Questionnaire score ${ }^{11}$ ranged from 0 to 13, with an average of 1.85 (SD 3.0). The highest score was for an individual with motor and visual difficulties due to bilateral hip arthrosis and diabetic retinopathy. Out of the total group, 23 individuals (54.76\%) had Pfeffer scores of 0 .

The Katz index ranged from 5 to 6, with an average of 5.90 (SD 0.30). The largest proportion of the participants (38 individuals; 90\%) had a Katz index of 6.

The Dementia Rating Scale ranged from 112 to 139, with a mean of 123 (SD 12.5). Semantic verbal fluency (in which the participants were asked to list supermarket items) ranged from 9 to 25, with a mean of 16 (SD 4.0).

The repetition of digits in direct order ranged from 4 to 6, with an average of 4.73 (SD 0.91) and for inverse order the score ranged from 2 to 6 , with a mean of 3.52 (SD 0.91).

The analysis of interhemispheric coherence for the alpha band at $\mathrm{O} 1 \mathrm{O} 2$ showed an average value of 0.65 (SD 0.13), and the value that appeared most frequently was 0.65 (14.63\% median), with a range of 0.48 to 0.98 .

\section{DISCUSSION}

We analyzed, in our study in $2007^{3}$, the interhemispheric coherence for the alpha band for eight pairs of electrodes distributed across the scalp, in normal individuals aged 20 to 50 years. The mean values found were 0.66 for P3 and P4, and 0.63 for $\mathrm{O} 1$ and $\mathrm{O} 2$. Thus, we observed that there was no significant difference between them (Mann-Whitney U test for independent samples with $\mathrm{p}<0.05$ ) (Figure).

However, in a study by Duffy et al. ${ }^{20}$, with 37 individuals aged 20-80 years, a significant decrease in coherence

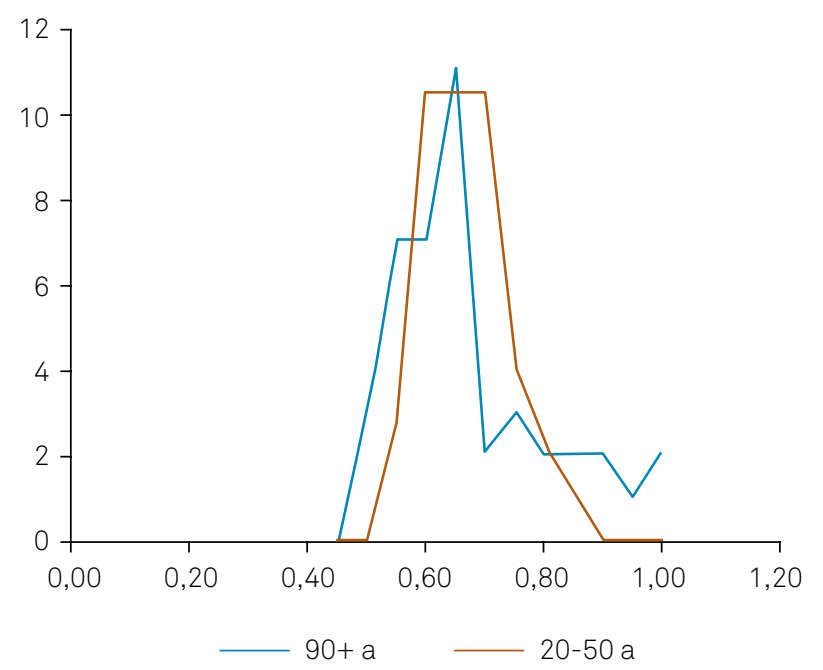

Figure. Alpha band0102 coherence frequency between age groups.

was found with increasing age. Moreover, in a study by Kikuchi et al. ${ }^{21}$, on interhemispheric coherence for several frequency bands among 55 healthy volunteers, comparing young and old, decreased coherence among older individuals (50-67 years) was also found.

Normal aging in humans is known to affect several aspects of central cholinergic function. This results in deficits in acetylcholine release levels and changes to muscarinic receptor plasticity. Hence, Sloan et al. ${ }^{22}$ demonstrated that when scopolamine (an anticholinergic drug) was administered to normal subjects, it decreased interhemispheric coherence in the alpha and beta bands. These findings suggest that a reduction in cholinergic activity is involved in the underlying normal mechanism of reduced coherence in elderly individuals.

Nevertheless, several different mechanisms appear to be involved in modulation of EEG coherence, such as corpus callosum integrity and thalamo-cortico-thalamic reverberation. Koeda et al..$^{23}$ and Montplaisir et al. ${ }^{24}$ demonstrated the importance of the corpus callosum in this analysis. These authors showed that individuals with agenesis of the corpus callosum, or those who were subjected to partial corpus callosotomy, presented with reduced interhemispheric coherence.

In our study, the maintenance of interhemispheric coherence values may have been due to the integrity of the corpus callosum in this age group. On the other hand, Weiss et al. ${ }^{25}$ demonstrated, through MRI, a reduction of the corpus callosum in normal elderly individuals. However, their participants were younger than ours. Moreover, among our individuals who underwent an MRI, no abnormality affecting the corpus callosum was detected.

Hogan et al..$^{26}$ studied the effects of aging on EEG coherence through comparison between young adults and normal elderly individuals. They also found that the coherence was lower among their healthy elderly group. However, they compared intrahemispheric coherence between the frontotemporal, frontocentral and temporoparietal regions, unlike our study in 
which we evaluated interhemispheric coherence. Other studies, such as that of Vysata et al..$^{18}$, demonstrated declines in the magnitude of interhemispheric coherence for the alpha and theta bands with aging, caused by reductions in cerebral connectivity.

Another factor that can interfere in the calculation of coherence between two points distant from the scalp is the type of reference used during the recording. Therefore, we used a linked binaural reference, which, according to data in the literature, such as in the study by Vysata et al. ${ }^{18}$, is the technique that interfered least in determining coherence in relation to the age of the individuals studied.

In the present study, we also compared interhemispheric coherence for the alpha band between men and women, and between the P3P4 and 0102 pairs of electrodes. We did not find any statistically significant differences (MannWhitney $U$ test; $\mathrm{p}<0.05)$. This may have been due to the small size of our sample, the prevalence of women (3:1), or the age group studied.

Our results were very close to those obtained by Anghinah et al.,27 in Brazilian populations over the age of 50 years (Table 2 ).
Table 2. Comparison between several studies on alpha band coherence at 0102

\begin{tabular}{lcc}
\hline Author & Age & Coherence mean \\
\hline Anghinah, 200027 & $>50$ years & 0.658 \\
Anghinah, 2005² & $>50$ years & 0.660 \\
Jorge, 2007 & $<50$ years & 0.637 \\
Jorge, 2017 & $90-100$ years & 0.657 \\
\hline
\end{tabular}

In addition, we did not find any correlation between MMSE scores and interhemispheric coherence values for the alpha band at 0102 (Pearson's correlation coefficient 0.31; $\mathrm{p}=0.05$ ).

In conclusion, the results obtained showed that the mean coherence value for the alpha band in the occipital regions in normal nonagenarian individuals was 0.65 , with a range from 0.48 to 0.98 . Therefore, our study did not show any decrease in interhemispheric coherence for the alpha band at the $\mathrm{O} 1 \mathrm{O} 2$ electrodes in this group. This may indicate that this represents a standard value for this age group. We also believe that further studies with a larger number of participants and with imaging tests may provide greater knowledge on this subject.

\section{References}

1. Silva FL. Computer-assisted EEG diagnosis: pattern recognition and brain mapping. In: Niedermeyer E, Silva FL, editors. Electrocephalography: basic principles, clinical applications, and related fields. 5th ed. Baltimore: Williams and Wilkins; 2005. p. 1233-63.

2. Anghinah R. EEG spectral coherence. Rev Neurociências. 2005;13(1):50-3.

3. Jorge MS, Botelho RV, Melo ACDP. Study of interhemispheric coherence on healthy adults. Arq Neuropsiquiatr. 2007;65(2B):377-80. https://doi.org/10.1590/S0004-282X2007000300002

4. Gotman J. The use computers in analysis and display of EEG and evoked potential. In: Daly DD, Pedley TA, editors. Current practice of clinical electroencephalography. 2nd ed. Philadelphia: Lippincott Williams \& Wilkins;1990. p. 51-83.

5. Cibils D. Análise da coerência na doença de Alzheimer e no envelhecimento normal. In: Anghinah R, Luccas FJC. A neurofisiologia clinica no auxílio diagnóstico das demências. São Paulo: Biosintética; 1999. p. 63-8.

6. Towle VL, Carder RK, Khorasani L, Lindberg D. Electrocorticographic coherence patterns. J Clin Neurophysiol. 1999;16(6):528-47. https://doi.org/10.1097/00004691-199911000-00005

7. Gudmundsson S, Runarsson TP, Sigurdsson S, Eiriksdottir G, Johnsen K. Reliability of quantitative EEG features. Clin Neurophysiol. 2007;118(10):2162-71. https://doi.org/10.1016/j.clinph.2007.06.018

8. Koyama K, Hirasawa H, Okubo Y, Karasawa A. Quantitative EEG correlates of normal aging in the elderly. Clin Electroencephalogr. 1997;28(3):160-5. https://doi.org/10.1177/155005949702800308

9. Smith GE, Ivnik RJ, Malec JF, Kokmen E, Tangalos EG, Kurland LT. Mayo's Older Americans Normative Studies (MOANS): factor structure of a core battery. Psychol Assess. 1992;4(3):382-90. https://doi.org/10.1037/1040-3590.4.3.382

10. Folstein MF, Folstein SE, McHugh PR. "Mini-mental state": a practical method for grading the cognitive state of patients for the clinician. J Psychiatr Res. 1975;12(3):189-98. https://doi.org/10.1016/0022-3956(75)90026-6
11. Pfeffer RI, Kurosaki TT, Harrah CH, Chance JM, Filos S. Measurement of functional activities in older adults in the community. J Gerontol. 1982;37(3):323-9. https://doi.org/10.1093/geronj/37.3.323

12. Katz S, Stroud MW. Functional assessment in geriatrics. J Am Geriatr Soc. 1989;37(3):267-72. https://doi.org/10.1111/j.1532-5415.1989.tb06820.

13. Mattis S. Mental status examination for organic mental syndromes in the elderly patient. In: Bellak L, Karasu TB, eds Geriatric psychiatry: a handbook for psychiatrists and primary care physicians. New York: Grune \& Stratton, 1976. p. 77-121.

14. Klem GH, Lüders HO, Jasper HH, Elger $\mathrm{C}$. The ten-twenty electrode system of the International Federation. Electroencephalogr Clin Neurophysiol Suppl. 1999;52(3):3-6.

15. Luccas FJC, Braga NIO, Fonseca LC, Frochtengarten ML. Recomendações para o registro e interpretação do mapeamento topográfico do eletrencefalograma (EEG) e potenciais evocados sensoriais (PES). Parte I: aspectos gerais. Braz J Epilepsy Clin Neurophysiol. 1996;2:175-82.

16. Rappelsberger P. The reference problem and mapping of coherence: a simulation study. Brain Topogr. 1989;2(1):63-72. https://doi.org/10.1007/BF01128844

17. Locatelli T, Cursi M, Liberati D, Franceschi M, Comi G. EEG coherence in Alzheimer's disease. Electroencephalogr Clin Neurophysiol. 1998;106(3):229-37. https://doi.org/10.1016/S0013-4694(97)00129-6

18. Vysata O, Kukal J, Prochazka A, Pazdera L, Simko J, Valis M. Age-related changes in EEG coherence. Neurol Neurochir Pol. 2014;48(1):35-8. https://doi.org/10.1016/j.pjnns.2013.09.001

19. Gonzalez Andino SL, Pascual Marqui RD, Valdes Sosa PA, Biscay Lirio R, Machado C, Diaz G et al. Brain electrical field measurements unaffected by linked earlobes reference. Electroencephalogr Clin Neurophysiol. 1990;75(3):155-60. https://doi.org/10.1016/0013-4694(90)90169-K

20. Duffy FH, Mcanulty GB, Albert MS. Effects of age upon interhemispheric EEG coherence in normal adults. Neurobiol Aging. 1996;17(4):587-99. https://doi.org/10.1016/0197-4580(96)00007-3 
21. Kikuchi M, Wada Y, Koshino Y, Nanbu Y,

Hashimoto T. Effect of normal aging upon interhemispheric EEG coherence: analysis during rest and photic stimulation Clin Electroencephalogr. 2000;31(4):170-4. https://doi.org/10.1177/155005940003100404

22. Sloan EP, Fenton GW, Standage KP. Anticholinergic drug effects on quantitative electroencephalogram, visual evoked potential, and verbal memory. Biol Psychiatry. 1992;31(6):600-6. https://doi.org/10.1016/0006-3223(92)90246-V

23. Koeda T, Knyazeva M, Njiokiktjien C, Jonkman EJ, De Sonneville L, Vildavsky V. The EEG in acallosal children. Coherence values in the resting state: left hemisphere compensatory mechanism? Electroencephalogr Clin Neurophysiol. 1995;95(6):397-407.

https://doi.org/10.1016/0013-4694(95)00171-9
24. Montplaisir J, Nielsen T, Côté J, Boivin D, Rouleau I,

Lapierre G. Interhemisphere EEG coherence before and after partial callosotomy. Clin Electroencephalogr. 1990;21(1):42-7. https://doi.org/10.1177/155005949002100114

25. Weis S, Kimbacher M, Wenger E, Neuhold A. Morphometric analysis of the corpus callosum using MR: correlation of measurements with aging in healthy individuals. AJNR Am J Neuroradiol. 1993;14(3):637-45.

26. Hogan M, Collins P, Keane M, Kilmartin L, Kaiser J,

Kenney $J$ et al. Electroencephalographic coherence, aging, and memory: distinct responses to background context and stimulus repetition in younger, older, and older declined groups. Exp Brain Res. 2011;212(2):241-55. https://doi.org/10.1007/s00221-011-2726-8

27. Anghinah R, Kanda PA, Jorge MS, Lima EE, Pascuzzi L, Melo AC. [Alpha band coherence analysis of EEG in healthy adult and Alzheimer's type dementia subjects]. Arq Neuropsiquiatr. 2000;58(2A):272-5. Portuguese. https://doi.org/10.1590/S0004-282X2000000200011 